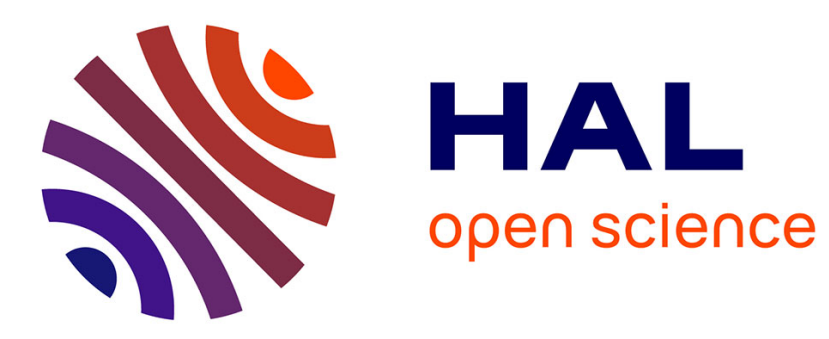

\title{
Reflexive paradigms in Khaling
}

Guillaume Jacques, Aimée Lahaussois, Dhan Bahadur Rai,

\section{To cite this version:}

Guillaume Jacques, Aimée Lahaussois, Dhan Bahadur Rai,. Reflexive paradigms in Khaling. Linguistics of the Tibeto-Burman Area, 2016, 39 (1), pp.33-48. 10.1075/ltba.39.1.02jac . hal-01356782

\section{HAL Id: hal-01356782 \\ https://hal.science/hal-01356782}

Submitted on 26 Aug 2016

HAL is a multi-disciplinary open access archive for the deposit and dissemination of scientific research documents, whether they are published or not. The documents may come from teaching and research institutions in France or abroad, or from public or private research centers.
L'archive ouverte pluridisciplinaire HAL, est destinée au dépôt et à la diffusion de documents scientifiques de niveau recherche, publiés ou non, émanant des établissements d'enseignement et de recherche français ou étrangers, des laboratoires publics ou privés. 


\title{
Reflexive paradigms in Khaling*
}

\author{
Guillaume Jacques \\ Aimée Lahaussois \\ Dhan Bahadur Rai
}

July 26, 2015

\begin{abstract}
Khaling, like other Kiranti languages, has a Reflexive / Middle suffix -si, the main function of which is to reduce the valence of verbs. The present paper describes the complex morphological alternations observed in the reflexive paradigms, and provides a detailed account of the various meanings of the -si derivation in Khaling.

Keywords: Khaling, Kiranti, reflexive, autobenefactive, middle, antipassive, anticausative, reciprocal
\end{abstract}

\section{Introduction}

Like all Kiranti languages, Khaling presents a reflexive conjugation distinct from the simplex intransitive conjugation described in Jacques et al. (2012). ${ }^{1}$ This paper describes the reflexive conjugation and presents the set of rules necessary to generate all regular forms. It is divided into three sections.

First, we present the set of affixes in the reflexive conjugation and compare it with the intransitive vowel-final conjugation. We also provide comparative data from closely related Kiranti languages and discuss the historical origin of the idiosyncrasies observed in these paradigms.

Second, we analyse the stem alternations observed in the reflexive paradigm, and show that the rules necessary to generate the forms have already been proposed in Jacques et al. (2012). Third, we describe the semantic values of reflexive derivation.

\footnotetext{
${ }^{*}$ This research was funded by the HimalCo project (ANR-12-CORP-0006) and is related to the research strand LR-4.11 "Automatic Paradigm Generation and Language Description" of the Labex EFL (funded by the ANR/CGI). We would like to thank two anonymous reviewers and the editors for insightful suggestions. Glosses follow the Leipzig glossing rules, to which we add HABIT habitual, IMPERS impersonal, SENS sensory.

${ }^{1}$ Toba (1984) includes one reflexive paradigm, but without any analysis of the stem alternations and of the semantics of the $-s i$ construction.
} 


\section{Affixal paradigm}

The conjugation of reflexive verbs is close to that of vowel-final intransitive verbs. As in other Kiranti languages (a more detailed comparison with Dumi, Wambule and Limbu is provided below), the paradigm includes a reflexive suffix whose main allomorph is $-s i$ in Khaling.

Table (1) lists the forms of the reflexive paradigm of $\mid$ ncm-si $\left.\right|^{2}$ nemsine "to immerse oneself, to dive", a verb chosen for its lack of stem alternations.

Table 1: The conjugation of $\mid$ nem-si $\mid$ "to immerse oneself"

\begin{tabular}{|c|c|c|c|}
\hline & non-past & past & imperative \\
\hline $1 \mathrm{~s}$ & \multirow{5}{*}{$\begin{array}{l}n \varepsilon m-s i-\eta \Lambda \\
n \varepsilon m-s i-j i \\
n \varepsilon m-s i-j u \\
n \varepsilon m-s i-k i \\
n \varepsilon m-s i-k \Lambda\end{array}$} & nem-tısu / nem-sinıtı & \\
\hline 1DI & & $n \varepsilon m-s \hat{1}-j t i$ & \\
\hline $1 \mathrm{DE}$ & & nem-sî-jtu & \\
\hline 1PI & & nem-si-ktiki & \\
\hline $1 \mathrm{PI}$ & & $n \varepsilon m-s i-k t \Lambda k \Lambda$ & \\
\hline $2 \mathrm{~S}$ & \multirow{3}{*}{ 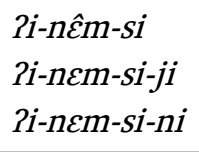 } & Pi-ncm-tE-si & nem-si-je \\
\hline $2 \mathrm{D}$ & & 2i-nEm-sî-jti & $n \bar{\varepsilon} m-s \hat{i}-j j e$ \\
\hline $2 \mathrm{P}$ & & Pi-ncm-tênnu & nem-nuje \\
\hline $3 \mathrm{~s}$ & \multirow{3}{*}{$\begin{array}{l}n \hat{\varepsilon} m-s i \\
n \varepsilon m-s i-j i \\
n \varepsilon m-s i-n u\end{array}$} & $n \varepsilon m-t \varepsilon-s i$ & \\
\hline $3 \mathrm{D}$ & & $n \varepsilon m-s \hat{1}-j t i$ & \\
\hline $3 \mathrm{P}$ & & nEm-tênnu & \\
\hline
\end{tabular}

This paradigm presents overabundance, as two competing variants are attested for all first person past forms: $\Sigma-t \Lambda s u$ and $\Sigma$-signtı.

The personal suffixes and prefixes of reflexive verbs are essentially the same as those of intransitive verbs with a vowel-final root, as a comparison with Table (3) shows. All non-past forms are fully predictable once the reflexive suffix $-s i$ is taken into account. In the rest of the paradigm, only three suffixes differ from those for non-reflexive verbs, and they are indicated in bold in Table (1).

The suffix -tısu for 1SG past is non-predictable from either the 1SG non-past form or from the rest of the past tense paradigm. The variant -sinsts on the other hand can be generated from the non-past suffix -sips following the same rule as simplex intransitive verbs (pi-pn 'I come', pi-pnts 'I came'). This suggests that -tısu is the inherited form, while -sinsts is analogically renewed from the rest of the paradigm, following four-part analogy (Hock 1991, 167-175), see Table 2.

The second and third person past -tênnu and the imperative plural -nuje do not present vowel syncope as do the regular suffixes of vowel final verbs -tnu and -nje. These reflexive suffixes are more similar to the suffixes found in consonant-final paradigms (-

\footnotetext{
${ }^{2}$ The verbs given in this format are the underlying roots used to generate paradigms. Conjugated verb forms exhibit stem alternations in the vowel, tone and final consonant.
} 
Table 2: Four-part analogy

\begin{tabular}{|c|c|c|}
\hline & simplex verb 'come' & reflexive verb 'immerse oneself' \\
\hline 1SG.N.PST & $p i-\eta\rceil \Lambda$ & $n \varepsilon m-\sin \Lambda$ \\
\hline 1SG.PST & $p i-\eta \eta \Lambda-t \Lambda$ & $n \varepsilon m-t \Lambda s u \rightarrow n \varepsilon m-\sin \Lambda-t \Lambda$ \\
\hline
\end{tabular}

tEnu and -nuje respectively for $2 / 3$ PL past and imperative respectively) which do not have vowel loss.

Table 3: Intransitive verb $p i$ "come (level)"

\begin{tabular}{|c|c|c|c|}
\hline & non-past & past & imperative \\
\hline $1 \mathrm{~S}$ & $p i-\eta \Lambda \Lambda$ & pi-putu & \\
\hline $1 \mathrm{DI}$ & $p i-j i$ & $p \hat{i}-j t i$ & \\
\hline $1 \mathrm{DE}$ & $p i-j u$ & pî-jtu & \\
\hline 1PI & $p i-k i$ & pi-ktiki & \\
\hline $1 \mathrm{PE}$ & $p i-k \Lambda$ & $p i-k t \Lambda k \Lambda$ & \\
\hline $2 \mathrm{~s}$ & 2i-pi & 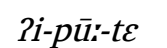 & $p \bar{u}{ }^{\prime}-j e$ \\
\hline $2 \mathrm{D}$ & 2i-pi-ji & Pi-pî-jti & pî-jje \\
\hline $2 \mathrm{P}$ & 2i-pi-ni & Pi-pūis-tnu & pû-nje \\
\hline $3 \mathrm{~s}$ & pi & pur-tE & \\
\hline $3 \mathrm{D}$ & $p i-j i$ & $p \hat{i-j t i}$ & \\
\hline $3 \mathrm{P}$ & $p i-n u$ & $p \bar{u} \cdot-t n u$ & \\
\hline
\end{tabular}

In most forms, the reflexive suffix -si appears between the verb stem and the personal suffixes. There are only three sets of exceptions to this rule:

- The second and third person singular forms, where -si occurs after the non-first person past marker $-t \varepsilon$, resulting in $-t \varepsilon$-si where we would have expected $\dagger-s i-t \varepsilon$.

- The second and third person plural forms, where $-s i$ has an allomorph $n$ occurring between the non-first person past marker $-t \varepsilon$ and the plural suffix $-n u$. The suffix in these forms is thus -tênnu instead of expected $\dagger-s i-t \varepsilon-n u$. It is unclear if a sound change ${ }^{*} s n>-n n$ - ever existed in Khaling; in any case the group $-s n$ - is attested across morpheme boundaries, as in the imperative plural of transitive $-t$ final verbs (ses-nuje "kill him" 2P >3, Jacques et al. 2012, 1118).

- The second plural imperative -nuje, which lacks an overt reflexive marker.

These particularities of the Khaling reflexive paradigm appear to be isolated among Kiranti languages. Even in Dumi, the closest relative of Khaling, the forms corresponding 
to Khaling 1SG past, 2SG/PL past and 3SG past are regular, as shown in Table (4). ${ }^{3}$

Table 4: Comparison of the Dumi and Khaling paradigms of the verb "to wash oneself"

\begin{tabular}{|c|c|c|}
\hline & Dumi & Khaling \\
\hline root & $\mid$ sir-si $\mid$ & $\mid$ sur-si $\mid$ \\
\hline $1 \mathrm{SG}$ & $s i r-s-t i$ & $s \Lambda r-s i-\eta n t \Lambda / s \Lambda r-t \Lambda-s u$ \\
\hline 1PI & sir-si-kti & sır-si-ktiki \\
\hline $2 \mathrm{SG}$ & $a-s i r-s-t i$ & $2 i-s \Lambda r-t \varepsilon-s i$ \\
\hline $2 \mathrm{PL}$ & a-sir-s-ti-ni & 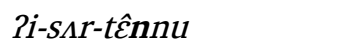 \\
\hline $3 \mathrm{SG}$ & $s i r-s-t i$ & $s \Delta r-t \varepsilon-s i$ \\
\hline
\end{tabular}

Table 4 compares our Khaling data (the verb |sur-si| "to wash oneself") with the paradigm in van Driem $(1993,125 ; 362-3)$. In Dumi, the reflexive has two allomorphs $-s$ and $-s i$, the selection of which depends on the following suffix.

Apart from this allomorphy, the reflexive suffix in Dumi does not merge with personal suffixes to form portmanteau morphemes, and it always occurs to the left of all personal suffixes.

\section{Stem alternations}

In comparison with consonant-final paradigms, which can present up to five distinct stems for intransitive verbs (see for instance Table 5) and twelve for transitive verbs, no more than three distinct stems need to be posited for any reflexive verb.

Table 5: Stem alternation of the consonant-final intransitive conjugation of $\mid k^{h}$ ot $\mid$ "to go"

\begin{tabular}{|c|c|}
\hline form & stem \\
\hline 1SG.NPST & $k^{h} O \hat{\jmath} j-\eta \Lambda \Lambda$ \\
\hline 1DI.NPST & $k^{h} \theta t s-i$ \\
\hline 1PI.NPST & $k^{h} O c_{c}-k i$ \\
\hline 3P.NPST & $k^{h} O \hat{\jmath} n-n u$ \\
\hline 1SG.PST & $k^{h} \theta S-t \Lambda$ \\
\hline 2 SG.IMP & $k^{h} \theta t s t s-e$ \\
\hline
\end{tabular}

The stem alternations observed in reflexive verbs can, with a few exceptions, be generated by the rules described in Jacques et al. (2012, 1108-1111). Verb stems in Khaling can be derived from roots following the syllabic template $C(r, l) V C_{f}(t)$ for which only six vowels $(|a|,|\varepsilon|,|e|,|i|,|o|,|u|)$ and eight final consonants $C_{f}(|-p|,|-t|$, $|-k|,|-m|,|-n|,|-\eta|,|-r|,|-l|)$ need to be distinguished. Some verbs have roots with final

\footnotetext{
${ }^{3}$ Note the suffix $-t$, the past marker in most other Kiranti languages, is the Dumi non-past marker. A past / non-past flip-flop has occurred.
} 
clusters in $|-C t|$ (hence the $C_{f} t$ in the template, cf Jacques et al. 2012, 1119-1122), but the reflexive derivation neutralizes the contrast between $C V C$ and $C V C t$ roots: the final cluster $|-C t|$ is simplified to $|-C|$ when a verb receives the suffix $-s i$.

In reflexive verbs, we find three distinct stems: a weak stem $\left(\Sigma_{1}\right)$, a strong stem $\left(\Sigma_{2}\right)$, and a nasalized strong stem $\left(\Sigma_{3}\right)$. Their distribution is shown in Table 6: the weak stem is found in all dual forms, the strong stem is restricted to first person plural, and the nasalized strong stem appears with all other forms (all singular forms and non-first person plural).

Table 6: Distribution of verbal stems in the Khaling reflexive paradigm

\begin{tabular}{|c|c|c|c|}
\hline $1 \mathrm{~s}$ & $\Sigma_{3}-S i-\eta \eta \Lambda$ & $\Sigma_{3}$-tusu $/ \Sigma_{3}$-sinutu & \\
\hline 1DI & $\Sigma_{1-s i-j i}$ & $\Sigma_{1}-s \hat{1}-j t i$ & \\
\hline $1 \mathrm{DE}$ & $\Sigma_{1-s i-j u}$ & $\Sigma_{1}-s \hat{-}-j t u$ & \\
\hline $1 \mathrm{PI}$ & $\Sigma_{2}-s i-k i$ & $\Sigma_{2}-s i-k t i k i$ & \\
\hline 1PI & $\Sigma_{2}-s i-k \Lambda$ & $\Sigma_{2}-s i-k t \wedge k \Lambda$ & \\
\hline $2 \mathrm{~S}$ & $2 i-\Sigma_{3}-s i$ & $2 i-\Sigma_{3}-t \varepsilon-s i$ & $\Sigma_{3}$-si-je \\
\hline $2 \mathrm{D}$ & $2 i-\Sigma_{1}-s i-j i$ & $2 i-\Sigma_{1}-s \hat{1}-j t i$ & $\Sigma_{1-s \hat{-}-j j e}$ \\
\hline $2 \mathrm{P}$ & $2 i-\Sigma_{3}-S i-n i$ & $2 i-\Sigma_{3}-t \hat{E} n n u$ & $\Sigma_{3}$-nuje \\
\hline $3 \mathrm{~s}$ & $\Sigma_{3}-S i$ & $\Sigma_{3}-t \varepsilon-s i$ & \\
\hline $3 \mathrm{D}$ & $\Sigma_{1-S i-j i}$ & $\Sigma_{1}-s \hat{1}-j t i$ & \\
\hline $3 \mathrm{P}$ & $\Sigma_{3}-s i-n u$ & $\Sigma_{3}$-tênnu & \\
\hline
\end{tabular}

In reflexive verbs, the following three rules are needed to derive the weak stem from the root:

1. The final dentals $|-t|$ and $|-n|$ change to $-s$, with lengthening of the preceding vowel in the case of $|-n|$. The other final consonants are not affected.

2. The back vowels $|o|$ and $|u|$ are fronted to $\boldsymbol{\theta}$ and $\boldsymbol{u}$ when not followed by a velar.

3. In the case of vowel-final roots, an $-s$ is inserted between the stem and the suffixes.

For the strong stem, the rules are the following:

1. Final $|-t|$ changes to $-\boldsymbol{s}$.

2. Final $|-n|$ changes to $-j$.

3. $|i|$ in closed syllables changes to $\Lambda$.

4. The back vowels $|o|$ and $|u|$ change to $\boldsymbol{o s}$ and $\Lambda$ in roots with a non-velar coda.

5. The back vowels $|o|$ and $|u|$ are fronted to $\theta$ and $\boldsymbol{u}$ in vowel-final roots.

6. In the case of vowel-final roots, an $-s$ is inserted between the stem and the suffixes. 
The nasalized strong stem shares rules with the strong stem 1-5 (but not rule 6), to which are added the following:

1. Root-final $|-p|,|-t|,|-k|$ change to the corresponding nasals $-m,-n,-\eta$ and the stem receives falling tone.

2. Root-final $|-\eta|$ changes to $-n$.

3. In the case of vowel-final roots, an $-\boldsymbol{n}$ is inserted between the stem and the suffixes and the stem receives falling tone.

The nasalization observed in the nasalized strong stem has been reported in most other Kiranti languages, and van Driem $(1993,127)$ accounts for a similar phenomenon in Dumi by positing an underlying form $|-n s i|$ for the cognate suffix. Although such an analysis may be valid from a diachronic point of view, it is unclear how to explain the absence of nasalization in dual and first person plural forms in Khaling, which unlike in Dumi are not subject to nasalization.

The stem alternations of reflexive paradigms have two particularities not found in the simple paradigms studied in Jacques et al. (2012).

First, the strong nasalized stems of sonorant-final roots do not receive a falling tone when followed by the past tense suffix $-t$, thus, while $n \hat{\varepsilon} m-t \varepsilon$ 'he immersed it' ( $3 \mathrm{SG}$ past) has a falling tone, the reflexive nem-te-si does not.

Second, there is no irregular conjugation for $|-a k|$ roots (unlike for simple intransitive verbs, cf Jacques et al. 2012, 1115).

These morphophonological alternations have been implemented in PERL and the paradigms generated by the script have been thoroughly revised with several native speakers. This computational application and its verification convincingly suggest that the analysis provided here can correctly be used to predict all forms.

However, not all speakers of Khaling, especially in the younger generation, feel confident about all the forms of the paradigms. In particular, in the case of vowel-final roots, the application of the above rules generates a paradigm with alternating $n$ and $s$, as in the case of $\mid$ no-si $\mid$ "to rest" (Table 7 ). Some speakers generalize the $n$-forms to the whole paradigm, resulting in a conjugation without any stem alternation.

\section{Syntax and semantics}

Detransitive $-s i$ verbs, aside from the morphology described above, present common morphosyntactic properties: they are intransitive both from the point of view of verbal morphology (absence of transitive direct or inverse markers) and from the point of view of case marking (no ergative on the S). However, the relationship between the $\mathrm{S}$ of the $-s i$ verb and the $\mathrm{A}$ and $\mathrm{P}$ of the base verb is not straightforward, and several subtypes can be distinguished.

In this section, we first study the various subtypes of detransitive $-s i$ derivation (reflexive, autobenefactive, reciprocal, antipassive, and impersonal). Then, we present 
Table 7: nônsine "to rest"

\begin{tabular}{|c|c|c|}
\hline & original paradigm & analogical paradigm \\
\hline $1 \mathrm{~S}$ & \multirow{2}{*}{$\begin{array}{l}\text { nênsinı } \\
\text { nessiji }\end{array}$} & nênsinı \\
\hline $1 \mathrm{DI}$ & & nônsiji \\
\hline $1 \mathrm{DE}$ & nessiju & nônsiju \\
\hline 1PI & nessiki & nônsiki \\
\hline $1 \mathrm{PE}$ & nessikn & nênsikı \\
\hline $2 \mathrm{~S}$ & Pinênsi & Pinênsi \\
\hline $2 \mathrm{D}$ & Pinessiji & Pinênsiji \\
\hline $2 \mathrm{P}$ & \multirow{2}{*}{$\begin{array}{l}\text { Pinênsini } \\
\text { nênsi }\end{array}$} & Pinênsini \\
\hline $3 \mathrm{~s}$ & & nênsi \\
\hline $3 \mathrm{D}$ & nessiji & nônsiji \\
\hline $3 \mathrm{P}$ & nônsinu & nênsinu \\
\hline
\end{tabular}

some additional semantic changes caused by this derivation. Although the diverse semantic effects associated with the -si derivation are reminiscent of the oft-cited category of 'middle', this fuzzy concept is of little help in describing in detail the specific uses of this derivation and we prefer to avoid it, opting for a more precise terminology.

\subsection{Categories}

There are five main subtypes of $-s i$ derivations. The reflexive, autobenefactive and impersonal subject interpretations of the - si derivation are productive, while the two remaining ones (reciprocal and antipassive) are each restricted to a few verbs.

\subsubsection{Reflexive}

The most common effect of $-s i$ is to derive a reflexive verb from a transitive one. The $\mathrm{S}$ of the reflexive verb corresponds to both the $\mathrm{A}$ and the $\mathrm{P}$ of the base verb; this can be represented by formula 1 .

(1) $\quad A=P \rightarrow S$

Example 2 illustrates three reflexive verbs derived from the transitive $\mid$ sent $\mid$ 'look at', $\mid$ sur| 'wash' and $\mid$ fur| 'wash hair'. The emphatic pronoun -tā:p is optional and its presence does not imply a reflexive interpretation. The transitive use of the base verb $\mid$ fur $\mid$ 'wash hair' is shown in 3, with the A marked in the ergative.

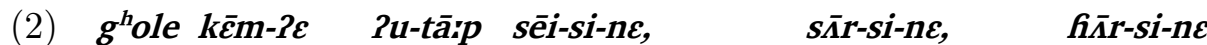

much work-ERG 3SG-self look.at-REFL-INF wash-REFL-INF wash.hair-REFL-INF

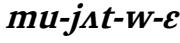

NEG-have.time-IRR-2/3 
Because of all this work, she did not have time to look after herself, to wash (her body) and her hair. (Solme Lamalit 31)

\section{(3) $\mathbf{P u}-\mathbf{m} \hat{\varepsilon} \boldsymbol{m}-\boldsymbol{P} \boldsymbol{\varepsilon}$}

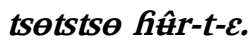

3SG.POSS-mother-ERG child wash.hair-PST-2/3

The mother washed her child's hair.

In some cases, the reflexive is derived from a verb with a historical $-t$ applicative post-final whose base form has disappeared. A good example is provided by | ipt| "put to sleep (vt)". *| ip| does not exist in Khaling (though cognates of it can be found even outside of Kiranti). The simplex verb has been replaced by the reflexive form of $\mid$ ipt|, | ipt-si| 'to sleep (vi)' (literally 'put oneself to sleep'). Interestingly, this replacement appears to be very old, as all Kiranti languages appear to form their verb 'to sleep' with a reflexive form, suggesting that in proto-Kiranti, the reflexive had already replaced the base intransitive verb. This process has typological parallels in other language families (for instance, French se coucher 'to go to bed' from coucher 'to put to bed').

\subsubsection{Autobenefactive}

Another very productive interpretation of the $-s i$ derivation is the autobenefactive, whereby the $\mathrm{A}$ of the base verb is converted to $\mathrm{S}$, with $\mathrm{P}$ remaining as an unmarked adjunct. It corresponds to 'indirect reflexive' in Kemmer (1993)'s terminology.

(4) $\quad A \rightarrow S$

$$
P \rightarrow \text { adjunct }
$$

This productive formation can be illustrated with |lom-si| 'search for oneself' as in 5; the transitive use of the base verb $|l o m|$ 'search, look for' is shown in 6 .

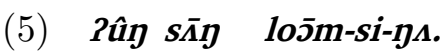

1SG wood search-REFL-1SG:S/P

I search for firewood for myself.

(6) $\boldsymbol{k}^{h} \boldsymbol{\theta} l e-? \varepsilon \boldsymbol{\varepsilon} \boldsymbol{p} \boldsymbol{p} \quad \mathbf{l o ̂} m-\mathbf{t}-\mathcal{\varepsilon}-\mathbf{n u}$

all-erg father search-PST-2/3-PL

They looked for the father. (Khamdime)

\subsubsection{Impersonal subject}

The impersonal subject interpretation of the $-s i$ derivation differs from the previous ones in that it can not only be applied to transitive verbs, but also to intransitive ones.

With transitive verbs, the impersonal subject $-s i$ construction implies either (i) a facilitative meaning, implying that the action takes place easily (with or without an agent) (ii) a passive meaning, with an unspecified agent that is still present semantically. Example 7 illustrates that the same surface sentence can have different interpretations depending on the context. 
(7) sâ: krîm-si.

vegetable cut-IMPERS.S/A

Passive: The green vegetables are cut (by someone).

Facilitative: The green vegetables cut easily.

With intransitive verbs, this form expresses an unspecified S argument, as in 8 .

(8) $\boldsymbol{k}^{\boldsymbol{h}} \boldsymbol{o} \boldsymbol{o ̂ n}-\boldsymbol{t \varepsilon}-\boldsymbol{s i}$.

gO-PST-IMPERS.S/A

(People) went (there).

The story 'The hunter and the old man' (based on true events) provided in the appendix of this paper illustrates a playful use of the impersonal subject forms. An old man asks a hunter about a hunt, and the young man, reluctant to give a clear answer, repeatedly uses impersonal forms of intransitive and transitive verbs to hide the identity of who did what during the hunt, in particular whether he or someone else was responsible for spotting a deer and killing it.

\subsubsection{Reciprocal}

The reciprocal interpretation of the $-s i$ derivation, like the reflexive one, entails a conversion of both the $\mathrm{A}$ and $\mathrm{P}$ of the transitive verb into the $\mathrm{S}$ of the intransitive one. However, in a reciprocal event, for two participants (or groups of participants) $x$ and $y$, a reciprocal event will involve $x$ acting on $y$ and $y$ acting on $x$ simultaneously or in alternation. Thus, such an interpretation is only possible with a non-singular S. As shown in 9, while both the $\mathrm{A}$ and $\mathrm{P}$ of the transitive verb correspond to the $\mathrm{S}$ of the $-s i$ verb, there is no identification of $\mathrm{A}$ and $\mathrm{P}$.

(9) $A \neq P \rightarrow S$ NS

Reciprocal interpretation is attested with verb whose semantics belong to Kemmer (1993)'s categories of 'naturally reciprocal events' and 'naturally collective actions'.

An example of the reciprocal use of $-s i$ is found in the verb $\left|p^{h} a k-s i\right|$ 'to separate', derived from $\left|p^{h} a k\right|$ 'to separate (vt)', as in examples

(10) dadubhai 2ok phak-si-ktıkı.

brothers 1PE separate-REFL-PST:1PE

We brothers separated.

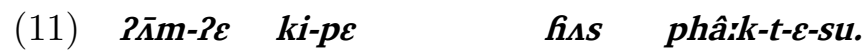

3SG-ERG fight-NMLZ:S/A person separate-PST-2/3-DU

He separated the fighting people. 


\subsubsection{Antipassive}

In the antipassive interpretation of the $-s i$ derivation, the $\mathrm{A}$ of the transitive base verb becomes $\mathrm{S}$ of the $-s i$ verb, while the $\mathrm{P}$ is deleted, but remains syntactically recoverable. The examples with such an interpretation group semantically around cognition and emotion verbs. The $\mathrm{A}$ of the transitive base verb and the $\mathrm{S}$ of the derived $-s i$ verb correspond to the experiencer, and the $\mathrm{P}$ of the base verb to the stimulus.

$$
\text { (12) } \begin{aligned}
A & \rightarrow S \\
P & \rightarrow \varnothing
\end{aligned}
$$

Example 13 illustrates this type of interpretation, in comparison with the base verb $\left|g^{h} r \varepsilon m t\right|$ 'be disgusted by' in 14 .

$g^{h} \bar{\varepsilon} \bar{m}-s i-\eta \underline{\Lambda}$

be.disgusted.by-REFL-1SG:S/P

I feel disgust.

(14) lokpei ghrēmd-u.

leech be.disgusted.by- $1 \mathrm{SG} \rightarrow 3$

I am disgusted by leeches.

The patient demoted during derivation can be recovered as an adjunct marked with the ablative $-k \Lambda 2 \Lambda$, as in 15 .

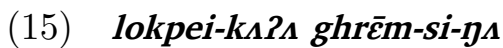

leech-ABL be.disgusted.by-REFL-1SG:S/P

I feel disgust because of leeches.

The verb $\mid$ mimt $\mid$ 'to think about' (example 16) and its derived form $\mid$ mimt-si | 'to think' present a case of antipassive derivation distinct from the previous one.

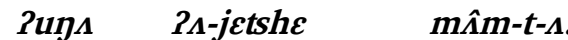

1SG:ERG 1SG.POSS-lover think.about-PST-1SG

I thought about my lover.

The derived verb $\mid$ mimt-si $\mid$ 'to think', like all antipassives, has the original A as its $\mathrm{S}$, but the original $\mathrm{P}$ is not recoverable with an ablative postpositional phrase. Instead, the stimulus can be expressed as direct speech, ${ }^{4}$ with a specific intonation, as in 17 .

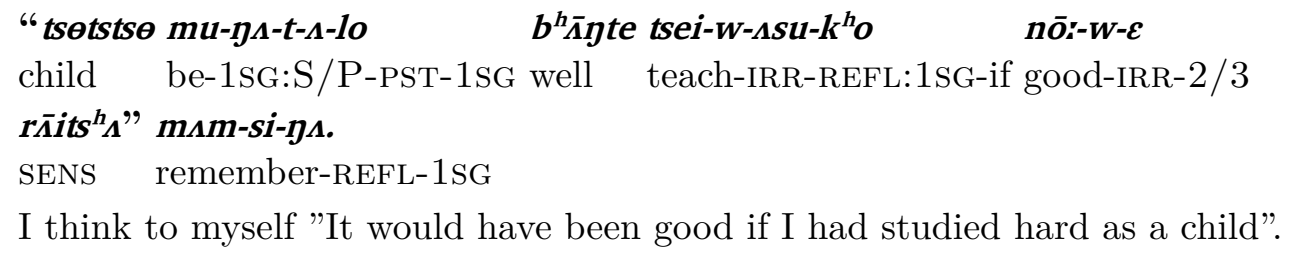

I think to myself "It would have been good if I had studied hard as a child".

\footnotetext{
${ }^{4}$ Direct speech is morphosyntactically recognizable as such because of the lack of nominalization, unlike other complement clauses.
} 
When $\mid$ mimt-si $\mid$ 'to think' appears with an NP as in 18, even though it might look like an unmarked adjunct corresponding to the original $\mathrm{P}$, the intonation makes it clear that here too, the NP in question is a nominal predicate expressed as direct speech.

(18) "PA-mêm-po

Pu-ge"

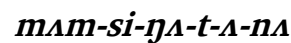

1SG.POSS-mother-GEN 3SG.POSS-clothes think.about-REFL-1SG-PST-1SG-SEQU

tû̀- $\boldsymbol{\eta}-\mathbf{t}-\boldsymbol{\Lambda}$.

put-1SG-PST-1SG

I thought: "These were my mother's clothes" and kept them.

\subsubsection{Multiple readings}

No verb allows all five possible distinct readings, but as a rule nearly all verbs can have multiple readings. The following examples illustrate the possible interpretation of the -si form with the root $\mid$ went $\mid$ 'cut, slice'; reciprocal and antipassive interpretations are not possible for this verb.

(19) Pups so wēnd-u.

1SG:ERG meat cut-1SG $\rightarrow 3$

I cut the meat.

(20) so wêi-si.

meat cut-REFL

Impersonal subject: 'The meat is cut (by someone)' OR 'The meat cuts easily'

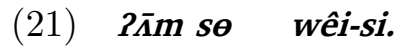

3SG meat cut-REFL

Autobenefactive: 'He cuts meat for himself.'

(22) $\boldsymbol{m}$ mu-wei-w-ısu.

NEG-cut-IRR-REFL:1SG:PST

Reflexive: 'I did not cut myself.'

\subsection{Irregularities}

The $-s i$ derivation, while very productive and regular, presents semantic ideosyncrasies involving lexical aspect or general meaning restricted to a few lexical items.

\subsubsection{Defective verbs}

Khaling has defective $-s i$ verbs, in other words verbs that do not have a corresponding transitive base form. There are three such verbs in our data, two of which are nontranslational motion verbs ( $\mid p^{h}$ op-si $\mid$ 'to bend', $\mid$ luk-si $\mid$, 'to bend one's body'), and another a natural reciprocal (|bray-si $\mid$, 'to separate'). We can surmise that the hypothetical base forms used to exist at an earlier stage (and traces may be found in related languages) but have disappeared in modern-day Khaling. 


\subsubsection{Intransitive}

Derivation in $-s i$ on intransitive verbs is strongly restricted to the impersonal subject interpretation. Yet, we find two cases where the $-s i$ derivation applies to an intransitive verb replacing the stimulus by the experiencer (Table 8).

Table 8: Stimulus to experiencer

\begin{tabular}{ll}
\hline Base verb & Derived verb \\
\hline tsePi 'to taste bad, to be unpleasant'. & tseRi-si 'to be embarrassed' \\
tsePnt 'be nice, be pleasant' & tse?nt-si 'feel nice' \\
\hline
\end{tabular}

\subsubsection{Unpredictable semantics}

Some - si detransitive verbs are semantically quite removed from the base verb, to the extent that it is not always easy to determine whether we have two homophonous but unrelated roots or whether an etymological relationship can be hypothesized.

An interesting example is provided by the transitive verb $\mid$ lunt $\mid$ whose meaning includes 'repeat, put a second layer of clothes, overlap' as in 23.

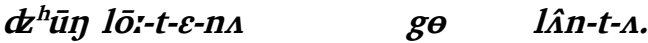

wind feel-PST-2/3-then clothes overlap-PST-1SG

As it was cold, I put a second layer of clothes.

Its derived form |lunt-si $\mid$ has very restricted meanings: 'put on a shaman garb' or the potentially metaphorical extension 'adopt a family name', as in 24 .

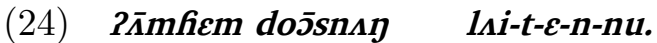

3PL family.name overlap-PST-2/3-REFL-PL

They adopted a family name.

While the meanings of the detransitive verb appears to be indirectly related to that of the transitive one, the exact path of semantic derivation is not recoverable without a deeper description of the local culture.

\section{Conclusion}

Reflexive derivation in $-s i$ in Khaling is quite rich and productive. It presents a few idiosyncratic phonological alternations in comparison with non-reflexive verbs, and its slot in the suffixal chain undergoes metathesis depending on the other suffixes present, resulting in some cases in verb forms such as $s \Lambda r-t-\varepsilon-s i$ wash-PST-2/3-REFL 'he washed himself' where the inflectional elements $-t$ - and $-\varepsilon$ are sandwiched between the stem and the derivational suffix $-s i$.

From the point of view of morphosyntax, the meaning of $-s i$ is not fully predictable. The basic meaning of this derivation is clearly reflexive, as this is the meaning observed 
for the largest number of examples. Yet, other detransitive interpretations are also attested for the suffix - si.

One possible interpretation is that the meaning of this suffix in proto-Kiranti (and earlier, as cognates of it appear in Kham and Dulong/Rawang) was specifically reflexive, and that all other interpretations secondarily derived from it through various pathways. Indeed, derivation from reflexive to anticausative, passive, or antipassive is widely attested (see Haspelmath 1990, Nedjalkov 2007, Say 2008), while the opposite pathway is not documented.

Another possibility is that the function of this suffix in the proto-language was much broader and already encompassed all types of detransitive derivation, but that only the reflexive interpretation was maintained solidly in Kiranti, while the other subtypes became restricted to a few items. This scenario is attractive as a very similar polysemy is found with - 6 ur, the cognate of $-s i$ in Dulong/Rawang (see in particular LaPolla \& Yang 2005). Yet, it is perhaps less probable in view of the fact that other valency decreasing derivations are reconstructible to proto-Kiranti, especially anticausative prenasalization (see Jacques 2013).

\section{Appendix}

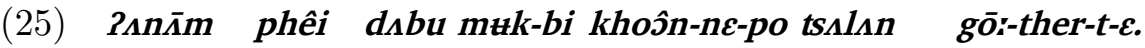
long.ago about hunt do-LOC go-INF-GEN tradition exist-HABIT-PST-2/3 Long ago, people used to hunt.

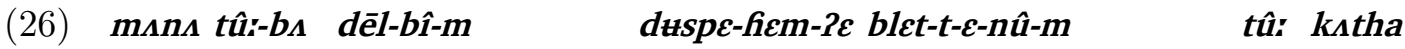
then one-CL village-LOC-NMLZ elder-PL-ERG tell-PST-2/3-PL-NMLZ one story tsent-pe ge.

be.nice-NMLZ:S/A exist

There is a nice story told by the elders of one village.

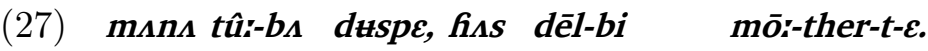

then one-CL elder man village-LOC exist-HABIT-PST- $2 / 3$

There used to be an elder man in the village.

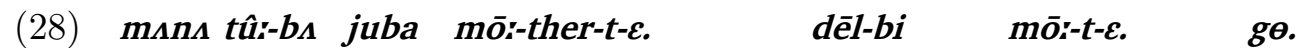
then one-CL youth exist-HABIT-PST- $2 / 3$ village-LOC exist-PST- $2 / 3$ exist And there used to be a young man in the village.

(29) manı 2̄̄m ts̄̄i dabu muk-ther-pe.

then 3SG TOP hunt do-HABIT-NMLZ:S/A

He used to hunt.

(30) munu tu-nôl me bure-fıss-kolo me sala-kolo

then one-day that elder-man-COMIT that young.man-COMIT

dum-i-t-i-nu, meet-2/3DU-PST-2/3DU-and 
Then, one day, that elder and that young man met.

(31) brâ: mu-s-su, s̄̄g lît-i-t-i,

word make-PST-DU ask RECIP-2/3DU-PST-2/3DU

They had a conversation, they asked each other questions.

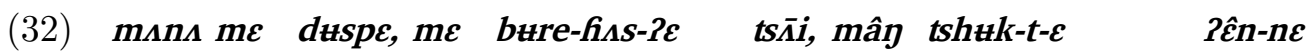

then that elder that elder-man-ERG TOP what happen-PST-2/3 say-INF

Pu-nû́-bejo ghole brâ: khể-t-e, mans me sala

3SG.POSS-mind-LOC:LEVEL a.lot word come.up-PST- $2 / 3$ then that young.man sîn-t-E-?e.

ask-PST-2/3-HEARSAY

The old man was wondering what had happened, and he asked the young man.

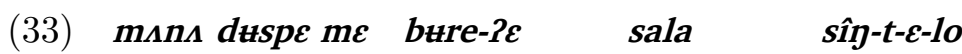

then elder that old.man-ERG young.man ask-PST-2/3-when

The old man asked the young man:

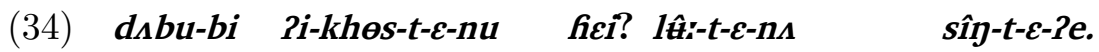

hunt-LOC 2-go-PST-2/3-PL QU tell-PST-2/3-and ask-PST-2/3-HEARSAY

He asked him: 'Did you ${ }_{p l}$ go hunting?'

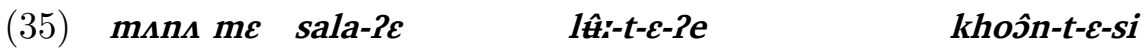

then that young.man-ERG tell-PST-2/3-HEARSAY go-PST-2/3-IMPERS:S/A

Then the young man told him: '(People) went'.

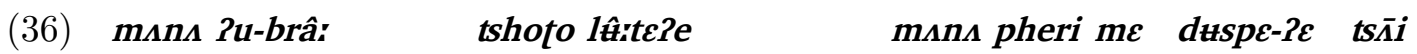
then 3SG.POSS-word short tell-PST-HEARSAY then again that elder-ERG TOP me sala sîn-t-e.

that young.man ask-PST- $2 / 3$

His answer (words) was short, and the old man asked the young man again:

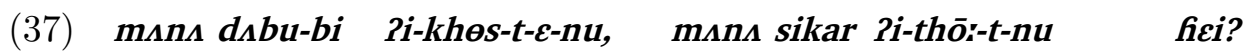

then hunt-LOC 2-go-PST-2/3-PL then game 2/INV-see-PST-PL QU

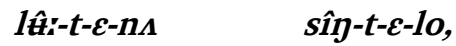

tell-PST-2/3-and ask-PST-2/3-when

He asked him 'So you went hunting, did you see game?'

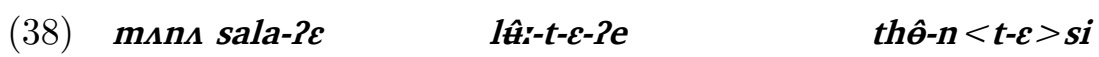

then young.man-ERG tell-PST-2/3-HEARSAY see- $<$ PST-2/3>IMPERS:S /A

The young man told him: '(It) was seen'.

(39) munı me sikar bhîr ni the-t-nu, munı mây tshuk-t-e me me

then that game deer TOP see-PST-PL then what happen-PST-2/3 that

duspe-Pe Podi mu-the-we,

elder-ERG idea NEG-see-IRR 
The old man (still) did not have a (clear) idea of what had happened; was the game that they saw a deer (or something else)?

(40) muns pheri sîn-t-દ-?e

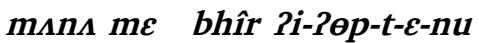

then again ask-PST-2/3-HEARSAY then that deer $2 /$ INV-shoot-PST-2/3-PL

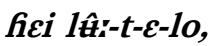

QU tell-PST-2/3-when

Then he asked again: 'Did you shoot that deer?'

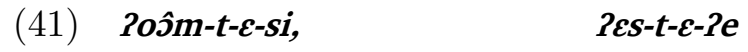

shoot-PST-2/3-IMPERS:S/A say-PST-2/3-HEARSAY

'(It) was shot'.

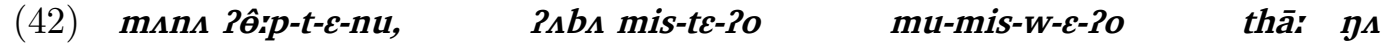

then shoot-PST-2/3-PL now die-PST-2/3-QU NEG-die-IRR-2/3-QU know FOC

mu-tshuk-w-E.

NEG-happen-IRR-2/3

So they had shot it, but now, did it die or not? (the old man still) did not know.

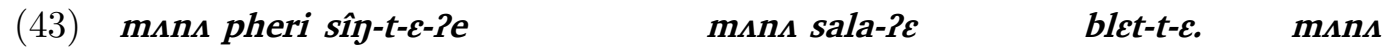

then again ask-PST-2/3-HEARSAY then young.man-ERG tell-PST-2/3 then

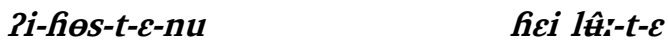

2/INV-bring.back-PST-2/3-PL QU tell-PST-2/3

Then he asked him again, and the young man told him; 'Did you bring it back?', he said.

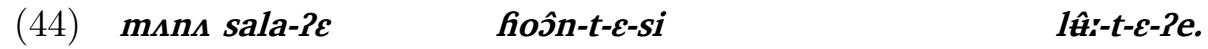

then young.man-ERG bring.back-PST-2/3-IMPERS:S/A tell-PST-2/3-HEARSAY

Then the young man said: 'It was brought back.'

\section{References}

van Driem, George. 1993. A Grammar of Dumi. Berlin: Mouton de Gruyter.

Haspelmath, Martin. 1990. The grammaticalization of passive morphology. Studies in Language 14.1. 25-72.

Hock, Hans Heinrich. 1991. Principles of Historical Linguistics. Berlin, New York: Mouton de Gruyter.

Jacques, Guillaume. 2013. Derivational morphology in Khaling. In Li Fang-Kuei Society for Chinese Linguistics, Young Scholar Symposium, University of Washington at Seattle.

Jacques, Guillaume, Aimée Lahaussois, Boyd Michailovsky \& Dhan Bahadur Rai. 2012. An overview of Khaling verbal morphology. Language and linguistics 13.6. 1095-1170. 
Kemmer, Suzanne. 1993. The Middle Voice. Amsterdam: Benjamins.

LaPolla, Randy \& Jiangling Yang. 2005. Reflexive and middle marking in Dulong/Rawang. Himalayan Linguistics 2. 1-13.

Nedjalkov, Vladimir P. 2007. Polysemy of reciprocal markers. In Vladimir P. Nedjalkov (ed.), Reciprocal constructions, 231-334. Amsterdam: Benjamins.

Say, Sergey S. 2008. K tipologii antipassivnyx konstrukcij: semantika, pragmatika, sintaksis: Rossijskaja akademija nauk, Institut lingvisticheskix issledovanij, St-Petersburg dissertation.

Toba, Sueyoshi. 1984. Khaling. Tokyo: ILCAA, Tokyo University of Foreign Studies. 